ORIGINAL ARTICLE

\title{
Perception and Determinants of Uptake of Preventive Health Services among the Staff of Obafemi Awolowo University, Ile-Ife, Osun State
}

\author{
Akinyemi PA, Afolabi OT, Adeomi AA, Olugbade OT \\ Department of Community Health, Obafemi Awolowo University, Ile-Ife, Osun State Nigeria.
}

Keywords
Preventive
health
services;
Routine
Medical
Examination;
Uptake;
Utilization;
University
workers

ABSTRACT

Background: The rising burden of chronic non-communicable diseases in Nigeria makes the need for preventive health services (PHS) imperative. Thus, this study assessed the perception and determinants of uptake of preventive health services among the staff of Obafemi Awolowo University, Ile-Ife, Osun State.

Methods: A cross-sectional analytical study was employed. Two hundred and ninety academic and non-academic staff of the university were enrolled in the study, using a stratified random sampling technique. The sample size was proportionally allocated to various subunits in the institution. Data were collected using a self-administered questionnaire. Determinants of uptake of PHS were assessed using binary logistic regression. A p-value of $<0.05$ was considered to be statistically significant.

Results: The majority of the respondents, $280(96.6 \%)$ had good perceptions of PHS, and 176 $(60.7 \%)$ reported barriers in access to PHS. Although a majority of the respondents, $268(92.4 \%)$ had positive attitudes towards PHS, most of the respondents $196(67.6 \%)$ had poor uptake. Common barriers to uptake of PHS were availability and affordability of the services, time constraints, and interference with other activities. Being an academic staff $(p=0.001)$ and presence of chronic illness $(p=0.043)$ were significant determinants of PHS uptake.

Conclusion: Uptake of PHS was poor among majority of the respondents despite their good perception of the services. This may be linked to the perceived barriers to access. Thus, there is a need for policy formulation and provision of an enabling environment by the University's authority for ease of access to PHS.

Correspondence to: Dr Patrick Ayodeji Akinyemi Department of Community Health, Obafemi Awolowo University, Ile-Ife, Osun State Nigeria. Email: kindepat@gmail.com Phone number: +234(0)8060073160

\section{INTRODUCTION}

Preventive health services comprise screening for diseases particularly, chronic non-communicable diseases and other peculiar diseases that clients are most at risk of having. ${ }^{1}$ It also offers counseling services on adoption of healthy lifestyles and disease prevention. Routine or periodic health examination is a form of preventive health services commonly 
adopted in many occupational health services to maintain the health of workers and enhance their productivity. ${ }^{2}$ Routine or periodic health examination (PHE) is a channel through which employees receive recommended health screening and interventions which assist them to remain in a state of fitness throughout their period of employment. ${ }^{3}$ The frequency of routine health examination usually varies in the range of annual or biannual based on the nature of workplace and their peculiar hazards. ${ }^{4}$

Various studies have shown that the uptake of preventive health services is poor. ${ }^{5-9}$ This has been partly associated with the poor prognosis of many chronic non-communicable diseases among blacks. The uptake of preventive health services is affected by factors that vary with different study areas. ${ }^{6,8-13}$ Awareness and level of knowledge of chronic noncommunicable diseases or hazards associated with employees' work were major factors observed to be affecting uptake of PHS.7,13 Other common factors identified include the religious beliefs, cultural practices; availability, accessibility, and affordability of preventive health services, and policy of the employers or workplace. Attitude and perception of chronic illness and PHS were also observed to affect the uptake of PHS.8,9,12

The university community comprises heterogeneous groups of workmen with varying job-specific occupational hazards. The frequency and degree of exposure to various classes of hazards vary with the job specification of university workers, hence, the need for an individualized periodic health examination. The university community is a well-structured community with fair representation of all professions and variations in sociodemographic variables as present in the general community. Major factors that have been identified as barriers to uptake of preventive health services include availability, accessibility, and affordability of preventive health services. This study focused on the intrapersonal factors affecting the uptake of preventive health services. Therefore, a university community was chosen for this study where preventive health services are readily available to all workers at the university health centre at affordable rates due to the availability of social health insurance for all university workers.

Nigeria, like other Sub-Saharan countries, has been experiencing rising prevalence of chronic non-communicable diseases. ${ }^{14}$ 
Early diagnosis through screening and treatment, coupled with the avoidance of modifiable risk factors, remains the key to controlling the rising scourge of these diseases. Preventive health services are important means of ensuring the prevention of risk factors for diseases, early diagnosis, and treatment of diseases, particularly among occupational groups. Therefore, identifying the determinants of uptake of these services within the university could form the basis for interventions to further improve uptake of the services. This study, therefore, aimed to assess the perception and determinants of uptake of PHS among university workers in Nigeria.

\section{METHODOLOGY}

Study location: This study was conducted at the Obafemi Awolowo University, IleIfe South-West Nigeria. It is a public university with a staff strength of 4,321 as at December 2020.15 This includes 1399 academic staff and 2922 non-academic staff. The university has a health centre that offers both preventive and curative services to members of the university community. The university health centre also offers pre-employment medical screening for staff and pre-admission medical screening for students. The university has an affiliated teaching hospital that serves as a referral centre for cases that could not be managed at the university health centre. Being a federal institution, all staff have access to a social health insurance scheme: the National Health Insurance Scheme. The students also have a compulsory insurance scheme, thus making the services offered at the centre affordable for all. The university has two colleges namely the College of Health Sciences and Postgraduate College. The academic unit of the university is divided into 14 faculties and 88 departments. The university also has 19 institutes and centres including the Centre for Distance Learning operating at the university's annex.

Study design and study population: The study was conducted using a crosssectional analytical design. The study population included academic and nonacademic staff. Temporary staff were excluded from the study because they were not enrolled in the social health insurance scheme and registration with the institution health services was not mandatory compared with the permanent staff.

Sample size and sampling technique: The sample size $(\mathrm{N})$ was calculated to get an 
absolute precision of $\pm 5 \%$ using the sample size formula for a single proportion. ${ }^{16}$ Since the study population is relatively small or finite (i.e., less than 10000), the finite population correction for proportions was used by dividing the sample size $\mathrm{N}$ by $1+[\mathrm{N}-1 / 10,000] .{ }^{16}$ After correcting for an anticipated non-response rate of $10 \%$, the sample size came to 290 . The sample size was calculated based on the proportion of the study population that undergo routine medical checkup regularly $(23.8 \%)$ in a similar study conducted among residents of Owo community in Ondo State, South-West Nigeria. ${ }^{17}$

The participants were stratified into academic and non-academic staff (stratified random sampling technique). The sample was proportionally allocated to the academic and non-academic staff at a ratio of 1:3 which was the average ratio of academic to non-academic staff according to the human resources unit of the institution. The non-academic staffs included the administrative officers, security officers, porters, librarians, cleaners, and laboratory staff that are on full-time employment with the institution. The proportion of the sample population assigned to the non-academic staff was allocated to these professions using stratified random sampling technique, with the sample size being proportionally allocated to the units of these aforementioned professions in the university. The list of staff in these different subgroups were obtained and participants were selected by systematic random sampling. Selected staff that were not present at work on the day of interview were replaced by the next eligible staff until the numbers allocated to these groups were completed.

Data collection: Data were collected using a self-administered questionnaire. The questionnaire was developed by the authors after a meticulous review of relevant literature and adaption from the tools developed for assessment of prostate cancer screening decision making and questionnaire for Well Man Clinic of Obafemi Awolowo University Teaching Hospital. Both tools have been validated and used in the study area. ${ }^{18}$ The questionnaire consisted of six sections: Section A contained questions on the socio-demographic data while Section B assessed the general health status and awareness of preventive health services. Section C contained questions on the uptake of preventive health services and 
the frequency of accessing the services. Section D assessed the attitude of respondents towards preventive health services. This section was rated on a 5point Likert scale where 1 represents "strongly disagree" and 5 represents "strongly agree". The scoring was, however, coded in reverse for negatively worded questions. Section E contained questions on the perception of preventive health services that were assessed based on the constructs of the Health Belief Model: perceived susceptibility, perceived severity, perceived barrier, cues to action, and self-efficacy. ${ }^{19}$ This section was rated on a 5-point Likert scale where 1 represents "strongly disagree" and 5 represents "strongly agree". Section F contained a list of services the respondents desired to access if preventive health service is to be established. The dependent variable was uptake of preventive health services while the independent variables include the socio-demographic variables, attitudes, and perception of preventive health services, and presence of chronic illness.

Data analysis: Data were analyzed using IBM SPSS version 25 for windows (IBM SPSS Inc., Chicago, USA). Mean and standard deviation was used to summarize continuous variables like age and average monthly income. Categorical variables were summarized using frequencies and proportions. Respondents who had a general medical examination within a year prior to the study were classified as having good uptake while those who had general medical examination more than a year prior to the survey or never had, were classified as poor uptake. Multiple response analysis was conducted to assess the services the respondents would be willing to uptake. The attitude and perceptions of various constructs of the health belief model were scored through the summation of scores of responses to the questions on a 5-point Likert scale, and the overall median score was calculated and used to categorize respondents. Those with scores up to the median score and above were considered to have a positive attitude or good perception, while those that scored below the median score were considered as having negative attitudes or poor perception towards preventive health services. Associations between sociodemographic variables and uptake of preventive health services were assessed using Pearson Chi-Square. Also, associations between independent variables like attitude and perception with 
the uptake of preventive health services were assessed using Pearson Chi-Square. Binary logistic regression was conducted to assess the determinants of uptake of preventive health services. The variables that had significant associations with the uptake of preventive health services at bivariate analysis level were entered into a regression model. A p-value of less than 0.05 was considered to be statistically significant.

Ethical considerations: Ethical approval was obtained from the Research and Ethics Committee of the Institute of Public Health (IPH), Obafemi Awolowo University, IleIfe, Nigeria (IPH/OAU/12/505). Verbal consent was sought from each respondent after an adequate explanation of the objectives of the study. Confidentiality and data security were assured. Participation was made voluntary as each participant was at liberty to opt-out at any point in the study.

\section{RESULTS}

In all, 290 staff of the university participated and completed the survey. The mean age of the respondents was 40.5 \pm 8.1 years. Majority of the respondents
$220(75.9 \%)$ were in the age range of 31 - 50 years. There were more male respondents, $203(70.0 \%)$ compared with the female, 87 $(30.0 \%)$. Majority of the respondents were Christians, 230 (79.3\%), and married, 234 $(80.7 \%)$. Most of the respondents were non-academic staff, 222 (76.6\%). (Table 1.) Less than half of the respondents, 136 $(46.9 \%)$ were aware of any existing preventive health services within their community. Employers, 37 (27.2\%) and religious bodies, 37 (27.2\%) were the major sources of information on preventive health services among those who aware of the existence of preventive health services. Most of the respondents perceived themselves to be in good states of health, $271(93.4 \%)$. About half (53.5\%) of the respondents visited doctors at least once within the last one year. Only very few respondents $20(6.9 \%)$ had chronic medical illnesses. The disclosure of specific illness was however poor. History of hypertension was the most common chronic medical illness reported by the respondents, $29(51.8 \%)$, followed by diabetes, 21 (37.5\%). Very few respondents reported history of other chronic medical illnesses like coronary heart disease, hyperlipidemia, and malignancies. 
Table 1: Sociodemographic characteristics of respondents

\begin{tabular}{ll}
\hline Variables & $\begin{array}{l}\text { Frequency } \mathbf{( n = 2 9 0 )} \\
\mathbf{n}(\mathbf{\%})\end{array}$ \\
\hline Age group (in years) & $40(13.8)$ \\
$21-30$ & $106(36.6)$ \\
$31-40$ & $114(39.3)$ \\
$41-50$ & $30(10.3)$ \\
51 and above & \\
Sex & $203(70.0)$ \\
Male & $87(30.0)$ \\
Female & \\
Religion & $57(19.7)$ \\
Islam & $230(79.3)$ \\
Christianity & $3(1.0)$ \\
Traditional religion & \\
Marital Status & $46(15.9)$ \\
Single/Never Married & $234(80.7)$ \\
Married & $6(2.1)$ \\
Separated/Divorced & $4(1.4)$ \\
Widowed & \\
Category of staff & $68(23.4)$ \\
Academic & $222(76.6)$ \\
Non-Academic & \\
Level of Education & $1(0.3)$ \\
Primary & $50(17.2)$ \\
Secondary & $239(82.5)$ \\
University & $74,227.5 \pm 73,996.0$ \\
Average Monthly Income (Naira) &
\end{tabular}

Mean age $\pm S D=40.5 \pm 8.1$ years

Majority of the respondents, 280 (96.6\%) had good perceptions of preventive health services. Majority of the respondents, 187 $(64.5 \%)$ had good perceptions of their susceptibility to chronic illness, while 228 (78.6\%) perceived chronic diseases that are preventable by PHS to be severe. Many respondents, $176 \quad(60.7 \%)$ had high perceived barriers in access and uptake of preventive health services; details are shown in Table 2. Positive attitudes towards preventive health services were observed among majority of the respondents, $268 \quad(92.4 \%)$ while the remaining 22 (7.6\%) had negative attitudes towards PHS. Description of variables used for the assessment of attitude towards preventive health services are as shown Table 3 below.

The uptake of preventive health services was however poor among the majority, 196 (67.6\%) About one-third of the respondents, 109 (37.6\%) had never participated in preventive health services, while $87(30.0 \%)$ of the respondents had periodic medical examinations done more 
Table 2: Perception of preventive health services among respondents

\begin{tabular}{ll}
\hline Variables & Frequency (\%) \\
\hline Perceived susceptibility to chronic diseases & $103(35.5)$ \\
Poor & $187(64.5)$ \\
Good & \\
Perceived severity of chronic diseases & $62(21.4)$ \\
Poor & $228(78.6)$ \\
Good & \\
Perceived barrier to uptake of PHS & $114(39.3)$ \\
Low & $176(60.7)$ \\
High & \\
Cue to Action & $6(2.1)$ \\
Poor & $284(97.9)$ \\
Good & $290(100.0)$ \\
Self-efficacy & $0(0.0)$ \\
Poor & $10(3.4)$ \\
Good & $280(96.6)$ \\
Overall perception of PHS & \\
Poor &
\end{tabular}

than a year prior to the study. Also, about one-third, $94(32.3 \%)$ of the respondents had periodic medical examinations within a year prior to the study. The commonly identified barriers to uptake were availability $140(48.3 \%)$, affordability 184 (63.4\%), time-consuming 201 (69.3\%), interference with other activities 159 $(54.9 \%)$ and the least barrier was religious belief $54(18.6 \%)$. Blood pressure check was the most common screening the respondents were willing to undergo 199 $(68.6 \%)$, followed by blood sugar test, 170 $(58.6 \%)$. The least desired services were health education on smoking 43 (14.8\%) and alcohol 49 (16.9\%). Details are shown in Table 4 below.
There was a significant association between the category of staff and uptake of preventive health services. The proportion of academic staff, 34 (50.0\%) with good uptake to preventive health services was significantly higher than the proportion with similar characteristics among nonacademic staff, $60(27.0 \%), p<0.001$. A higher proportion of people with good perceptions of preventive health services, $92(32.9 \%)$ had a good uptake of preventive health services compared with the proportion of respondents with poor perception who had a good uptake of preventive health services, $2(20.0 \%)$. The association between perception and uptake of preventive screening services 
Table 3: Respondents' attitude towards preventive health services

\begin{tabular}{lccc}
\hline Variables & $\begin{array}{c}\text { Agree } \\
\text { n (\%) }\end{array}$ & $\begin{array}{c}\text { Indifferent } \\
\text { n (\%) }\end{array}$ & $\begin{array}{c}\text { Disagree } \\
\text { n (\%) }\end{array}$ \\
\hline $\begin{array}{l}\text { It is important I get tested } \\
\text { routinely to prevent diseases }\end{array}$ & $269(92.8)$ & $9(3.1)$ & $12(4.1)$ \\
$\begin{array}{l}\text { Diseases usually resolve } \\
\text { spontaneously if I delay in } \\
\text { seeking care. }\end{array}$ & $52(17.9)$ & $26(9.0)$ & $212(73.1)$ \\
$\begin{array}{l}\text { I avoid seeing doctors/health } \\
\text { care workers whenever its } \\
\text { possible. }\end{array}$ & $75(25.9)$ & $27(9.3)$ & $188(64.8)$ \\
$\begin{array}{l}\text { I only access health care when } \\
\text { there is no other option. }\end{array}$ & $97(33.5)$ & $18(6.2)$ & $175(60.3)$ \\
$\begin{array}{l}\text { People should go for general } \\
\text { check at regular interval even if } \\
\text { the person feels well. }\end{array}$ & $207(71.4)$ & $18(6.2)$ & $65(22.4)$ \\
$\begin{array}{l}\text { I cut down workload to reduce } \\
\text { stress. }\end{array}$ & $201(69.3)$ & $51(17.6)$ & $38(13.1)$ \\
$\begin{array}{l}\text { I get more rest and sleep to be } \\
\text { healthy. }\end{array}$ & $252(86.9)$ & $27(9.3)$ & $11(3.8)$ \\
$\begin{array}{l}\text { I usually restrict intake of some } \\
\text { favourite but unhealthy foods. }\end{array}$ & $195(67.2)$ & $58(20.0)$ & $37(12.8)$ \\
$\begin{array}{l}\text { I get more involved in physical } \\
\text { exercise. }\end{array}$ & $246(84.8)$ & $27(9.3)$ & $17(5.9)$ \\
$\begin{array}{l}\text { Abstinence/cessation of } \\
\text { smoking is good for my health. }\end{array}$ & $139(47.9)$ & $82(28.3)$ & $69(23.8)$ \\
$\begin{array}{l}\text { Abstinence/cessation of alcohol } \\
\text { intake is good for my health. }\end{array}$ & $132(45.5)$ & $80(27.6)$ & $78(26.9)$ \\
\hline$n=290$ & & &
\end{tabular}

was however not statistically significant, $\mathrm{p}$ $=0.393$. The association between uptake of preventive health services and other respondents' characteristics like age, sex religion, marital status, level of education, and attitude towards preventive health services were not statistically significant. Details are shown in Table 5.

Category of staff and the presence of chronic illness were significant determinants of preventive health services uptake.

Academic staff were 2.5 times more likely to take up preventive health services compared with non-academic staff, $\mathrm{p}=$ 0.001. Also, the respondents with chronic illnesses were 3.7 times more likely to take up preventive health services than those without any chronic medical condition, $\mathrm{p}$ $=0.043$. Details are shown in Table 6 . 
Table 4: Uptake of preventive health services among university staff

\begin{tabular}{ll}
\hline Variables & Frequency (\%) \\
\hline Uptake of PHS & $196(67.6)$ \\
Poor & $94(32.4)$ \\
Good & \\
Frequency of uptake & $109(37.6)$ \\
Never & $87(30.0)$ \\
More than a year before the survey & $70(24.1)$ \\
Less than a year before the survey & $14(4.8)$ \\
A month before the survey & $10(3.4)$ \\
A week before the survey & \\
Barriers to uptake of PHS* & $201(69.3)$ \\
Time constraints & $184(63.4)$ \\
Affordability & $159(54.9)$ \\
Interference with other activities & $140(48.3)$ \\
Availability & $54(18.6)$ \\
Religious beliefs & \\
PHSs respondents are willing to uptake* & $199(68.6)$ \\
Blood pressure & $170(58.6)$ \\
Blood sugar & $127(43.8)$ \\
Weight & $121(41.7)$ \\
Blood fat & $110(37.9)$ \\
Diet talk & $109(37.6)$ \\
Exercise talk & $89(30.7)$ \\
Sexual behaviour talk & $54(18.6)$ \\
Breast lump screening & $49(16.9)$ \\
Alcohol talk & $43(14.8)$ \\
Smoking talk & $42(14.5)$ \\
Cervical screening & n=290 Multiple responses PHS - Preventive Health Services
\end{tabular}

\section{DISCUSSION}

Less than half of the respondents were aware of any existing preventive health services. The poor level of awareness could be due to poor sensitization in the workplace. The level of awareness was lower than the findings from a similar study conducted among the Chinese where more than three quarters $(68.0 \%)$ were aware of PHS..$^{20}$ This could be due to variation in the socio-cultural environments and health systems of the countries where the studies were conducted. The level of awareness of PHS was also lower compared with findings from a similar study conducted among male civil servants in Kaduna where 9 out of 10 respondents were aware of PHS. ${ }^{3}$ 
Table 5: Association between respondents' characteristics and uptake of preventive health services

\begin{tabular}{|c|c|c|c|}
\hline \multirow[t]{2}{*}{ Variables } & \multicolumn{2}{|c|}{ Uptake of Preventive Health Services } & \multirow[t]{2}{*}{ Test Statistics } \\
\hline & $\begin{array}{l}\text { Poor }(n=196) \\
n(\%)\end{array}$ & $\begin{array}{l}\text { Good }(n=94) \\
n(\%)\end{array}$ & \\
\hline \multicolumn{4}{|l|}{ Age group (in years) } \\
\hline $21-30$ & $22(55.0)$ & $18(45.0)$ & $X^{2}=3.542$ \\
\hline $31-40$ & $75(70.8)$ & $31(29.2)$ & $\mathrm{df}=3$ \\
\hline $41-50$ & 79 (69.3) & $35(30.7)$ & $p=0.315$ \\
\hline $51-60$ & $20(66.7)$ & $10(33.3)$ & \\
\hline \multicolumn{4}{|l|}{ Sex } \\
\hline Male & $140(69.0)$ & $63(31.0)$ & $X^{2}=0.588$ \\
\hline Female & $56(64.4)$ & $31(35.6)$ & $\begin{array}{l}d f=1 \\
p=0.443\end{array}$ \\
\hline \multicolumn{4}{|l|}{ Religion } \\
\hline Islam & $42(73.7)$ & $15(26.3)$ & $\mathrm{LR}=3.743$ \\
\hline Christianity & $151(65.7)$ & $79(34.3)$ & $\mathrm{df}=2$ \\
\hline Traditional Religion & $3(100.0)$ & $0(0.0)$ & $p=0.154$ \\
\hline \multicolumn{4}{|l|}{ Marital Status } \\
\hline Single Never Married & 33 (71.7) & $13(28.3)$ & $\mathrm{LR}=0.479$ \\
\hline Married & $156(66.7)$ & 78 (33.3) & $\mathrm{df}=2$ \\
\hline Divorced/Widowed & $7(70.0)$ & $3(30.0)$ & $p=0.787$ \\
\hline \multicolumn{4}{|l|}{ Occupation } \\
\hline Academic & $34(50.0)$ & $34(50.0)$ & $X^{2}=12.540$ \\
\hline Non-Academic & $162(73.0)$ & $60(27.0)$ & $\begin{array}{l}\mathrm{df}=1 \\
\mathrm{p}<0.001\end{array}$ \\
\hline \multicolumn{4}{|l|}{ Level of Education } \\
\hline Secondary & $35(68.6)$ & $35(68.6)$ & $X^{2}=0.031$ \\
\hline Tertiary & $161(67.4)$ & $161(67.4)$ & $\begin{array}{l}d f=1 \\
p=0.861\end{array}$ \\
\hline \multicolumn{4}{|l|}{$\begin{array}{l}\text { Presence of Chronic } \\
\text { Illness }\end{array}$} \\
\hline No & $188(69.6)$ & $82(30.4)$ & $X^{2}=7.462$ \\
\hline Yes & $8(40.0)$ & $12(60.0)$ & $\begin{array}{l}\mathrm{df}=1 \\
\mathrm{p}=0.006\end{array}$ \\
\hline \multicolumn{4}{|l|}{ Attitude } \\
\hline Negative & $11(50.0)$ & $11(50.0)$ & $X^{2}=3.361$ \\
\hline Positive & $185(69.0)$ & $83(31.0)$ & $\begin{array}{l}\mathrm{df}=1 \\
p=0.067\end{array}$ \\
\hline \multicolumn{4}{|l|}{ Overall Perception } \\
\hline Poor & $8(80.0)$ & $2(20.0)$ & $X^{2}=0.729$ \\
\hline Good & $188(67.1)$ & $92(32.9)$ & $\begin{array}{l}\mathrm{df}=1 \\
p=0.393\end{array}$ \\
\hline
\end{tabular}

LR = Likelihood Ratio

Majority of the respondents perceived respondents were below forty years. The themselves to be in good states of health. apparently healthy state could also be due This could be due to the age range of the to the long latency period of most NCDs. ${ }^{21}$ respondents because half of the 
Table 6: Binary logistic regression showing determinants of uptake of preventive health services

\begin{tabular}{|c|c|c|c|}
\hline Variables & Odds Ratio & $95 \% \mathrm{CI}$ & p-value \\
\hline \multicolumn{4}{|l|}{ Category of Staff } \\
\hline Non-Academic & Ref & & \\
\hline Academic & 2.5 & $1.438-4.480$ & 0.001 \\
\hline \multicolumn{4}{|l|}{$\begin{array}{l}\text { Presence of } \\
\text { chronic illness }\end{array}$} \\
\hline No & Ref & & \\
\hline Yes & 3.7 & $1.041-12.909$ & 0.043 \\
\hline
\end{tabular}

The uptake of preventive health services was poor among about three-quarters of the respondents. Being academic staff and having a chronic illness were the determinants of uptake of PHS. The presence of chronic illness requires frequent hospital visitation and exposure to health education. The improvement in the level of knowledge as a result of health education received may increase the uptake of PHS in order to prevent likely comorbidities. ${ }^{11,22-26}$ This is similar to the study conducted among Korean workers which showed that having at least one chronic disease was associated with a higher uptake of preventive health services. ${ }^{10}$ There was no significant association between religion and uptake of PHS. This is contrary to findings from a study conducted by Ibrahim and Odusanya among healthcare workers in Lagos where religion was a significant factor affecting PHS against breast cancer. ${ }^{27}$ This study is in agreement with the findings from similar studies where availability, accessibility, and affordability were the major barriers to uptake of PHS.11,28,29 The challenge of affordability may be due to non-coverage of PHS by social health insurance. The challenge with the availability of PHS may be due to poor sensitization of staff. The high proportion of respondents with good attitudes and perceptions towards preventive health services did not translate to good uptake of PHS. This is similar to the findings from a study conducted among women in Ibadan where only about one-tenth of the respondents had ever undergone cervical cancer screening despite good perceptions and attitudes towards screening services among the participants. ${ }^{5}$ The poor awareness and uptake of PHS among the university workers is of importance as most preventable non-communicable diseases will remain undiagnosed till the late stage of the diseases, usually with poor prognosis. 
Limitations: This study was conducted among workers in a public university community. This may not be representative of other public and private universities. Conducting a similar study in multiple universities is recommended. The respondents were initially reluctant to divulge their medical history. This was however overcome by reassurance of confidentiality and administration of questionnaires in the environment chosen by the respondents to ensure privacy.

Conclusion: The utilization of preventive health services was poor among the respondents despite a high proportion with positive attitudes and perceptions about PHS. The major determinants of uptake of PHS were being an academic staff and having a chronic medical condition. Although majority of the respondents perceived themselves to be in a good state of health, there is still a need for regular uptake of PHS because of the long latent period of most chronic noncommunicable diseases. Therefore, there is a need for intervention to improve the uptake of PHS in the university community. The department of public health and the university health centre need to create more awareness of the existence of PHS within the university and affiliated teaching hospital. The university authority also needs to enact a policy that will mandate the uptake of routine medical screening for the workers as this will enhance the quality of life of the workers and their productivity.

Acknowledgments: We will like to acknowledge the staff of the Obafemi Awolowo University for their contribution to this study. We will also like to acknowledge the staff of the Planning and Development Unit of the same institution for the provision of background data used in this study.

Conflict of interest: No conflict of interest

Source of funding: Self-sponsored

Authors' contributions: The research was led by the principal investigator, PAA. OTA participated in the conceptualization of the research work. All co-authors (PAA, OTA, AAA, OTO) participated in development of the questionnaire used for the study and coordination of data collection. Data analysis was done by PAA, while PAA, AAA, and OTO, were involved in manuscript writing. All authors were involved in the review of manuscript and effecting corrections suggested by the reviewers.

\section{REFERENCES}

1. Office of Disease Prevention and Health Promotion. Clinical preventive care. 2020; [cited June 22, 2020] Available from: https://www.healthypeople.gov/2020/le ading-health-indicators/2020-lhitopics/Clinical-Preventive-Services. 
2. Odukunle OA. Fundamental of occupational health and wellness. 2nd Edition ed. Lagos, Nigeria.2015.

3. Asuke S, Babatunde JM, Ibrahim MS. A comparative analysis of the awareness and practice of periodic health examination among workers of public and private establishments in Zaria, Northwestern Nigeria. Archives of Medicine and Surgery. 2017; 2(2): 38. https://doi.org/ 10.4103/archms.archms_50_17

4. Asogwa SE. A Guide to Occupational Health Practice in Developing Countries. Enugu, Nigeria: Snaap Press; 2012.

5. Ilevbare OE, Adegoke AA, Adelowo CM. Drivers of cervical cancer screening uptake in Ibadan, Nigeria. Heliyon. 2020; 6(3): e03505-e03505.

https://doi.org/10.1016/j.heliyon.2020.e0 $\underline{3505}$

6. Martin JY, Schiff MA, Weiss NS, Urban RR. Racial disparities in the utilization of preventive health services among older women with early-stage endometrial cancer enrolled in Medicare. Cancer Med. 2017; 6(9): 2153-2163.

https://doi.org/ 10.1002/cam4.1141

7. Ndikom CM, Ofi BA. Awareness, perception and factors affecting utilization of cervical cancer screening services among women in Ibadan, Nigeria: A qualitative study.

Reproductive Health. 2012; 9(1): 11. https://doi.org/10.1186/1742-4755-9-11

8. Ofoli JN, Ashau-Oladipo T, Hati SS, Ati L, Ede V. Preventive healthcare uptake in private hospitals in Nigeria: a crosssectional survey (Nisa premier hospital). BMC Health Services Research. 2020; 20: 110. https://doi.org/10.1186/s12913-020$\underline{05117-5}$

9. Ogden LL, Richards CL, Shenson D. Clinical preventive services for older adults: The interface between personal health care and public health services.
American Journal of Public Health. 2012; 102(3): 419-425.

https://doi.org/10.2105/AJPH.2011.3003

$\underline{53}$

10. Kim S, Song JH, Oh YM, Park SM. Disparities in the utilisation of preventive health services by the employment status: An analysis of 2007-2012 South Korean national survey. PLOS ONE. 2018; 13(12): e0207737.

https://doi.org/10.1371/journal.pone.020 $\underline{7737}$

11. Latunji O, Akinyemi O. Factors influencing health-seeking behaviour among civil servants in Ibadan, Nigeria. Annals of Ibadan Postgraduate Medicine. 2018; 16(1): 52-60.

12. Lee $\mathrm{SH}$, Joh H-K, Kim S, Oh S-W, Lee CM, Kwon H. Income disparities in the use of health screening services among university students in Korea: A crosssectional study of 2479 participants in a university. Medicine. 2016; 95(20): e3681. https://doi.org/10.1097/md.00000000000 $\underline{03681}$

13. Mugassa AM, Frumence G. Factors influencing the uptake of cervical cancer screening services in Tanzania: A health system perspective from national and district levels. Nursing Open. 2020; 7(1): 345-354.

https://doi.org/10.1002/nop2.395

14. World Health Organisation. Nigeria: Noncommunicable Diseases. 2018; [cited 28/04/2020]. Available from: https://www.who.int/nmh/countries/n ga_en.pdf.

15. Obafemi Awolowo University. History of the University. 2020;

https://oauife.edu.ng/aboutoau/history.

16. Katz DL, Elmore JG, Wild DMG, Lucan SC. Jekel's Epidemiology, Biostatistics, Preventive Medicine and Public Health. 4th Edition ed: Elsevier Saunder; 2014. 
17. Ilesanmi O, Omotoso B, Alele F, Amenkhienan I. Periodic medical checkup: Knowledge and practice in a community in South West Nigeria. International Journal of Public Health Research. 2015; 5: 576-583.

18. Department of Community Health. Wellman's clinic health screening questionnaire. In: Obafemi Awolowo University Teaching Hospital; 2014.

19. World Health Organisation. Health education: Theoretical concepts, effectiveness strategies and core competencies. Cairo, Egypt: World Health Organisation; 2012.

20. Chen CC, Lin YJ, Lin YT. Awareness and utilization of preventive care services among the elderly under National Health Insurance. International Journal of Health Care Finance and Economics. 2013; 13(3-4): 247-260. https:// doi.org/ 10.1007/s10754$\underline{013-9128-3}$

21. Balogh-Reynolds Joanna. Self-Rated Health Status' Influence on Utilization of Clinical Preventive Services [Dissertation]: Nursing Science, Carlow University; 2017.

22. Hategekimana C, Karamouzian M. Selfperceived mental health status and uptake of fecal occult blood test for colorectal cancer screening in Canada: A crosssectional study. International Journal of Health Policy and Management. 2016; 5(6): 365-371.

https://dx.doi.org/10.15171/ijhpm.2016. $\underline{14}$

23. Ajani SR, Susan HA, Oluwaseun A. Gender differences in factors associated with overweight and obesity among civil servants in Lagos, Nigeria. International Journal of Nutrition and Metabolism. 2015; 7(6): 66-73.
24. Ige I, Owoaje E, Adebiyi O. Non communicable disease and risky behaviour in an urban university community Nigeria. African Health Sciences. 2013; 13(1): 62-67. https://doi.org/10.4314/ahs.v13i1.9.

25. John AO, Emmanuel OO. Knowledge and practices of preventive sexual and reproductive health behaviours among male civil servants in Southwestern Nigeria. European Journal of Preventive Medicine. 2017; 5(6): 91. https://doi.org/10.11648/j.ejpm.2017050 $\underline{6.13}$

26. Momin MH, Desai VK, Kavishwar AB. Study of socio-demographic factors affecting prevalence of hypertension among bank employees of Surat City. Indian Journal of Public Health. 2012; 56(1): 44. doi: https://doi.org/10.4103/0019-557x.96970

27. Ibrahim NA, Odusanya OO. Knowledge of risk factors, beliefs and practices of female healthcare professionals towards breast cancer in a tertiary institution in Lagos, Nigeria. BMC Cancer. 2009; 9(1): 76. https://doi.org/10.1186/1471-2407-9-76

28. Bassey LA, Olaoji SI, Ifeanyi EO, Victor U, Oti AM. Utilization of prostate cancer screening services in the Niger Delta region of Nigeria: Situation analysis and implications for oncology social workers. European Journal of Scientific Research 2019; 154(3): 280-293.

29. Oguoma VM, Nwose EU, Skinner TC, Digban KA, Onyia IC, Richards RS. Prevalence of cardiovascular disease risk factors among a Nigerian adult population: Relationship with income level and accessibility to CVD risks screening. BMC Public Health. 2015; 15(1): 397. https://doi.org/10.1186/s12889-015$\underline{1709-2}$ 